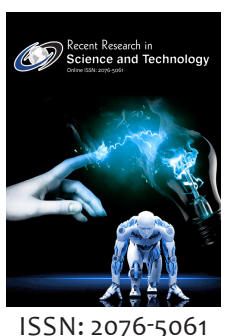

*Corresponding Author: Pema Lhamo Email: pema.Ihamo@post. auw.edu.bd

\section{Assessing the influence of human settlements on the plant diversity in wetlands of Phobji and Gangtey, Bhutan}

\author{
Pema Lhamo*, Ahmedul Kabir, Sayed Mohammad Nazim Uddin
}

Department of Environmental Science, Asian University for Women, Chattogram, Bangladesh

\begin{abstract}
Plant diversity in the wetlands of Phobji and Gangtey represents an important aspect of the overall wetland ecosystem. However, over the years, the increasing trend in population has initiated the building of many infrastructures and accommodations which lie at close proximity to the core wetland area. The plant diversity in human settled area and core undisturbed area was studied, with an objective to assess the influence of human settlement on the plant diversity. A belt transect method was used for the purpose of vegetation survey and Shannon Wiener diversity was calculated using the relative dominance. Plants were analyzed for their diversity, richness, dominance and invasive nature. Additionally, soil and water parameters were also tested to see the current situation of the $\mathrm{pH}$ and nutrient levels. A total of 136 species belonging to 39 families was identified in both the areas. The overall diversity index and species richness was found to be higher in the undisturbed areas. Soil analysis did not show much of a difference in physical and chemical parameters except for a slight difference in potassium content. Similarly, water parameters did not show much difference but only showed variation in calcium content. The findings of the study indicated towards the increasing influence of human settlement in the wetland.
\end{abstract}

KEYWORDS: Wetland, plant diversity, plant dominance, life forms, soil and water properties

\section{INTRODUCTION}

Wetlands constitute around 6\% of the total land on earth and harbors many biodiversity. They are also important for the world as they act as a carbon sink which absorbs the carbon content from the atmosphere (Meng et al., 2016) [3]. Amongst the many wetlands in Bhutan, the Gangtey-Phobjikha wetland is one of the most diverse wetlands which harbors as many as 300 threatened and vulnerable species including the black-necked crane (Grus nigricollis). (Ramsar.org, 2012) [5]. Wetlands also have the ability to retain the optimum parameters like water and soil to a certain extent (Zedler, et al 2005) [9]. However, threats and risks are usually imposed on the wetlands by varying factors. The changes in the wetlands are often attributed to climatic conditions but human intervention and developmental activities have also contributed to the degrading ecosystem of the wetland and its organisms (Lhendup, $\mathrm{P}$ and Webb, E.L., 2011) [2]. Thus, it becomes essential to conduct more research on the root causes and current situation of any degradation in the plant diversity. This study, thus was carried out to identify the various plant species in two areas; human settlement areas with prevalence of houses, roads and agriculture farms and the undisturbed core area where human disturbance is comparatively less. The primary objective of the study is to analyse the human settlement impact on the plant diversity in the conservation site of the wetlands of Phobji and Gangety. The research thus, specifically aims to aassess and compare the plant diversity in areas in human settled area and undisturbed core wetland areas. The research also aims to compare and analyse the soil and water parameters between the human settled areas and comparatively undisturbed core wetland area.

\section{METHODOLOGY}

\section{Study Site}

The wetlands in Gangtey-Phobji is one of the largest wetlands in the country and also the wintering grounds for one of the migratory black necked crane which has been listed as vulnerable by the International Union for the Conservation of Nature (IUCN). This wetland was also identified as wetland of

Copyright: $\odot$ The authors. This article is open access and licensed under the terms of the Creative Commons Attribution License (http://creativecommons.org/licenses/by/4.0/) which permits unrestricted, use, distribution and reproduction in any medium, or format for any purpose, even commercially provided the work is properly cited. Attribution - You must give appropriate credit, provide a link to the license, and indicate if changes were made. 
international importance listed under RAMSAR convention. The study site covered an approximate distance of 1000 meters along the Gangtey and Phobji wetlands. Phobji and Gangtey fall in the category of cool temperate zone. Lying at an elevation of 2900 meters above the sea level, the average temperature, recorded for 10 years till 2017 was found to be 8.2 degree Celsius and the average maximum temperature was recorded to be 14.7 degree Celsius. The average lowest temperature recorded was 0.2 degree Celsius (Climate book of Bhutan, 2018) [1]. The average maximum rainfall, for the past twenty years till 2015, was recorded in July.

\section{Vegetation Survey}

For the purpose of vegetation survey, the study site was classified as 'human settled area' and 'undisturbed core area', whereby the human settled area consisted of built infrastructures like houses, farmlands, roads and, the undisturbed area covered the core reserved area which serves as the main roosting area of the black necked crane. Survey and sampling was done in ten plots of which, the two classified areas comprised of five plots each. The vegetation survey was done in accordance to the standard procedures followed by Wangda et al., (2006) [7]. A ground layer level of vegetation survey was conducted. A belt transect system was exercised while surveying the vegetation of the plot which was divided into 10 quadrats $(1 \times 1 \mathrm{~m})$ to ensure maximum identification of species. In each of the quadrat, all identifiable plant species was listed with the help of the two plant experts and flora books of Bhutan. The height $(\mathrm{cm})$ of the tallest plant belonging to each species was measured till the tip of the foliage and also estimated for the percent coverage in each quadrat. As for the unidentifiable plants, a herbarium was prepared for further identification at the National Biodiversity Center, Thimphu Bhutan. Plant diversity was calculated using the Shannon Weiner Index (1) and the dominant analysis was conducted using formula (2) from (Ohsawa, 1984) [4].

$$
H^{\prime}=\sum_{i=1}^{s}-\left(P_{i}^{*} \quad L n P_{i}\right) \quad P_{i}=\frac{n_{i}}{N}
$$

where, $H^{\prime}=$ Shannon Weiner index

$n i=$ Numc $n_{i}=$ Number of individuals of species"

$\mathrm{N}=$ Total number of individuals of all species,

$P_{i}=$ Relative abundance of species

$S=$ Total number of species

$$
\begin{array}{r}
d=1 / N\left\{\sum\left(x_{i}-x^{\prime}\right)^{2}+\sum x_{j}^{2}\right\} \\
i \in T \quad j \in U
\end{array}
$$

Where $\chi_{i}=$ the actual percent share (relative basal area) of the top species $(\mathrm{T})$. In a one dominated model, there is only one ' $\mathrm{T}$ ' and in a two dominated model, ' $\mathrm{T}$ ' is two and so on.

$\chi^{\prime}=$ the ideal percent share

$\chi_{\mathrm{i}}=$ the percent share of the remaining species $(\mathrm{U})$

$\mathrm{N}=$ Total number of species

\section{Soil and Water Parameter}

A total of ten soil and water samples, five each from human settled area and undisturbed core area was collected and taken for analysis in the lab. For soil, parameters like pH, NPK content, total nitrogen and carbon were tested. For water, parameters like $\mathrm{pH}$. Electirc conductivity, Calcium $(\mathrm{mg} / \mathrm{l})$ and magnesium $(\mathrm{mg} / \mathrm{l})$ were tested. All the tests followed the protocol of SPAL (Soil and plant analytical lab) in Simtokha, Bhutan.

\section{RESULTS}

\section{Floristic Composition in Human Settled Area and Undisturbed Core Area}

A total 136 species under 39 families was found in the ground level vegetation analysis. In the human settled area, 79 species were found belonging to 27 families where as in the undisturbed area, 106 species were found belonging to 35 families. These counts showed that more number of species belonged to the comparatively less disturbed core wetland area.

\section{Plant Diversity and Richness}

The results from the Shannon Weiner's diversity index showed a high diversity index in HS4 of the human settlement area with an index of 3.12 (Figure 1). This plot was located below the roadside which could be a reason for growth of invasive or alien plants, ultimately leading to the increased diversity. In a similar study, Zangmo (2014) [8] also found that diversity along the roadside had the highest diversity index. Overall, average diversity index of the undisturbed area was 2.54 whereas the average diversity index of the human settled areas was 2.46. Although the overall diversity index of the undisturbed area was a bit higher than the human settled area, there was only a slight difference in the indices. (Figure 1)

In terms of species richness, the highest richness was recorded in UDl of the undisturbed area with 53 species identified. Overall, the species richness was found to be higher in the undisturbed area corresponding to the diversity index. Even in the case of the plot with the high diversity index, the species richness was comparatively higher than the rest of the plots in human settlement areas (Figure 1).

\section{Dominant Analysis}

Dominant Analysis found a total of 13 species in the undisturbed areas whereas in the human settled area, there were a total of 19 dominant species (Table 1). Among the ten plots, the highest number of dominant species was found in human settled area. In the human settled area, the common dominant species was Trifolium repens. Studies have shown that Trifolium repens was introduced in Bhutan in order to use a fodder for the livestock but now, it has spread to a lot of places which is negatively influencing the native plants (Roder, 2007) [6]. This might be the reason why Trifolium repens was found as one of the dominant species in human settlement area. In terms of the 


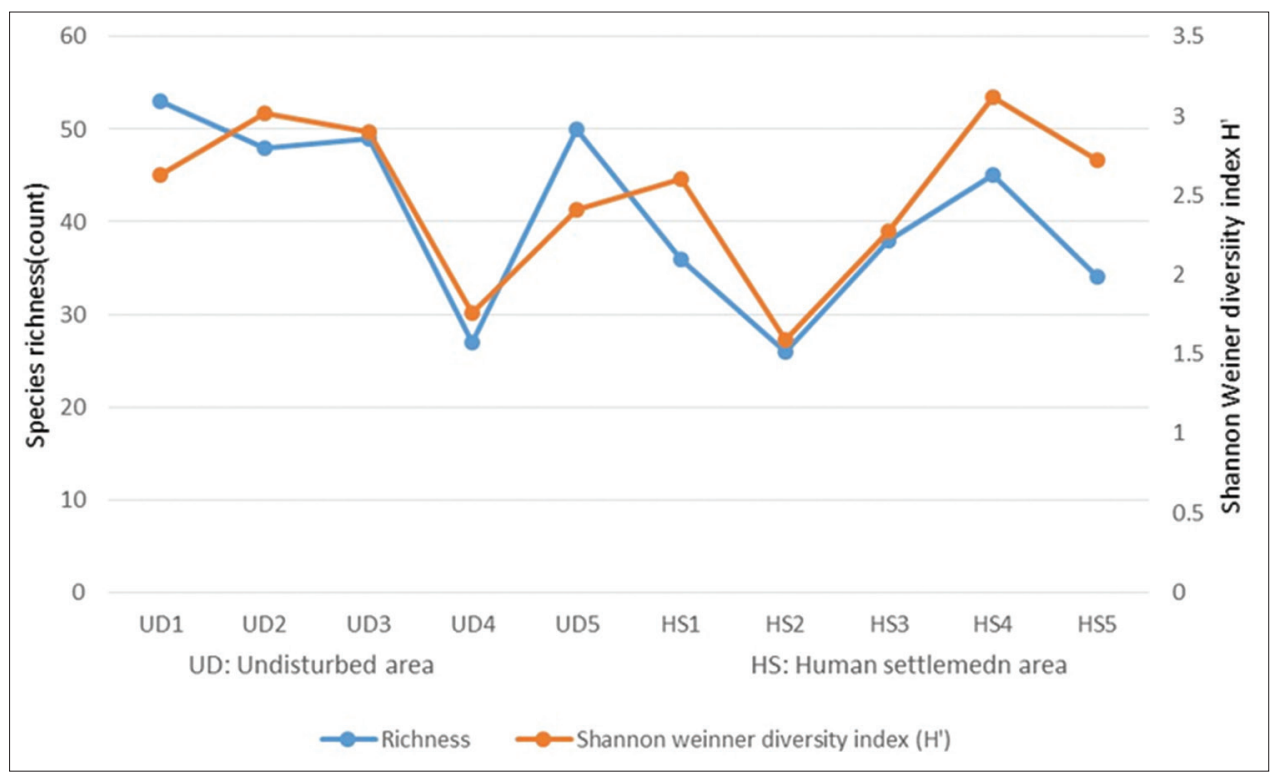

Figure 1: Species richness and Shannon Weiner index of the study area

Table 1: Dominant species in undisturbed and human settlement area

\begin{tabular}{|c|c|c|c|c|c|c|c|c|c|c|}
\hline \multirow[b]{2}{*}{ Species } & \multicolumn{5}{|c|}{ Undisturbed area } & \multicolumn{5}{|c|}{ Human settlement area } \\
\hline & UD1 & UD2 & UD3 & UD4 & UD5 & HS1 & HS2 & HS3 & HS4 & HS5 \\
\hline $\begin{array}{l}\text { Trifolium } \\
\text { repens }\end{array}$ & 9.87 & & & & 30.81 & 30.58 & 36.12 & 43.25 & & 26.52 \\
\hline $\begin{array}{l}\text { Primula } \\
\text { denticulata }\end{array}$ & & 26.5 & 32.15 & 32.15 & & & & & 15.52 & \\
\hline $\begin{array}{l}\text { Rumex } \\
\text { nepalensis }\end{array}$ & & & & & 8.37 & 6.14 & & & & 16.28 \\
\hline
\end{tabular}

undisturbed area, the common dominant species was Primula denticulata. The prevalence of this species is common in Western and Central parts of Bhutan (NBC) which is why it was found in abundance in the study area.

\section{Soil and Water Parameter}

The soil of the study area did not reveal much of a difference in the chemical parameters. In terms of total nitrogen, the undisturbed area had a percentage of $2.04 \%$ as compared to the human settlement area with a percentage of $1.52 \%$. Similarly, in terms of carbon content, undisturbed area showed $11.83 \%$ as compared to human settlement area with over $9.62 \%$. The average $\mathrm{pH}$ was found to be 5.43 in human settled area and 5.38 in undisturbed area. Even in terms of available phosphorus and potassium, the variations was very little. Phosphorus content was 1.76 and $0.70(\mathrm{mg} / \mathrm{kg})$ in undisturbed area and human settled area respectively. In terms of potassium, the tests recorded 68.93 and $79.32(\mathrm{mg} / \mathrm{kg})$ in undisturbed and human settled areas respectively.

The result showed that the water sample analysis like electric conductivity, $\mathrm{pH}$, calcium and magnesium, did not show much of a difference in the study areas. The study showed a constant direct electric conductivity (EC) of 0.10 . However, the average $\mathrm{pH}$ was recorded 6.39 in human settled area followed by 6.20 in the undisturbed area indicating a slightly acidic water in Gangtey and Phobji. The Magnesium content showed a similar value $(1.5-1.6 \mathrm{mg} / \mathrm{l})$ in the study area. However, the calcium content of $21.31 \mathrm{mg} / \mathrm{l}$ in the human settled area is found relatively higher than the undisturbed area with only $14.75 \mathrm{mg} /$. This can indicate that calcium is retained in the water, from the fertilizers applied in agriculture field.

\section{CONCLUSION AND RECOMMENDATIONS}

The wetlands of Phobji and Gangtey is undeniably homing a lot of diverse plant species. However, one of the major risks imposed on these diversity is human settlements. Over the years, Gangtey and Phobji has seen a rise in population and with that, a lot of other accommodations and infrastructures has started to rise in number as well. The effect of these interventions are starting to show in the plant diversity as seen in the result and discussion section. The diversity pattern showed slight variations, especially in terms of species richness.

The wetland in Phobji and Gangtey were mostly dominated by plant species such as Trifolium repens, Anaphalis nepalensis, Primula denticulata, Eleocharis congesta and Rumex nepalensis. Some of these species are alien and invasive in nature which increases the risk it poses on the overall plant diversity. In terms of soil parameters and water parameters, the variations in the 
parameters tested were not drastic. Only some parameter like potassium content in soil and calcium content in water had a huge variation. Overall, currently, the soil and water parameters indicated that there is only a little negative impact of human settlement on soil and water in the wetlands. However, the slight variations also indicate the starting trend of these negative issues. Thus, a strict policy needs to be made in order to reduce the impact of these human settlement. Proper waste management system needs to be introduced in the area. Additionally, frequent research and monitoring needs to be done in order to closely monitor the situation of plant diversity and other variables in the wetlands. More detailed study needs to be done in soil and water parameters in order to find any traces of eutrophication. The findings from this study can be used as a baseline for future studies in order to find any sort of significant changes in the variables of the ecosystem.

\section{ACKNOWLEDGEMENT}

I would like to extend my profound gratitude to Asian University for Women for funding the research. I also would like to thank Dr. Ahmedul Kabir, Dr. Sayed Mohammad Nazim Uddin, Dr. Pema Wangda, Dr. Jamyang, Mr, Dawa Tshering, Mr. Kelzang Tobgyal, Mr. Tshering, and Ms. Pema Yangzom for your valuable guidance and support. I am also very grateful to all the staffs of SPAL for your support.

\section{REFERENCES}

1. Climate Book of Bhutan. 2018. National Center for Hydrology and Meteorology. Royal Government of Bhutan. Retrieved from http://nchm.gov.bt/attachment/ckfinder/userfiles/files/Climate\%20 Data\%20Book\%20of\%20Bhutan\%2C\%202018.pdf

2. Lhendup, P., and Webb, E.L., 2009. Black-necked Cranes Grus nigricollis in Bhutan: migration routes, threats and conservation prospects. Forktail, 25(2009), pp.125-129.

3. Meng, L, Roulet, N, Zhuang, Q, Christensen, TR \& Frolking, S 2016 'Focus on the impact of climate change on wetland ecosystems and carbon dynamics', Environmental Research Letters, vol. 11, no. 10, 100201. https://doi.org/10.1088/1748-9326/11/10/100201.

4. Ohsawa, M., 1984. Differentiation of vegetation zones and species strategies in the subalpine region of Mt. Fuji. Vegetatio, 57(1), pp.15-52.

5. Ramsar.org. (2012). Bhutan's third Ramsar Site | Ramsar. [online] Available at: https://www.ramsar.org/news/bhutans-third-ramsar-site [Accessed 11 Feb. 2019].

6. Roder, W., Dorji, K. and Wangdi, K., 2007. Implications of white clover introduction in East Himalayan grasslands. Mountain Research and Development, 27(3), pp.268-274.

7. Wangda, P., Gayltshen, D., Tenzin, K., Ghemiray, D.K., and Pradhan, R. (2006). Influence of farm road on the herbaceous composition of the Black-necked Crane (Grus negricollis) habitat at Phobjikha valley. Royal Society for Protection of Nature.

8. Zangmo, J. (2014). 'Effect of Land use Type on Floristic Diversity and Composition in Wetland area of Phobjika, Wangdue', Master's thesis, Royal University of Bhutan. Lobesa.

9. Zedler, J.B. and Kercher, S., 2005. Wetland resources: status, trends, ecosystem services, and restorability. Annul. Rev. Environ. Resources 30, pp.39-74. 